\section{ONOMAREDIN}

Revista semestral de lingüística, filología y traducción
PONTIFICIA UNIVERSIDAD CATÓLICA DE CHILE CATOLICA DE CHILE
FACULTAD DE LETRAS

\title{
Enunciación y percepción: la evidencialidad en los textos turísticos del español
}

Enunciation and perception: evidentiality

in Spanish tourist texts

\section{Belén Alvarado Ortega \\ Universidad de Alicante \\ España}

\section{(c) $\underset{\mathrm{BY}}{\mathrm{N}} \bigodot_{\mathrm{ND}}$}

Belén Alvarado Ortega: Departamento de Filología Española, Lingüística General y Teoría de la Literatura, Facultad de Filosofía y Letras, Universidad de Alicante, España. Grupo GRIALE.

| Correo electrónico: belen.alvarado@ua.es 


\title{
Resumen:
}

Este trabajo pretende ofrecer una propuesta de estudio basada en la modalidad del enunciado y en la relación que existe entre esta y la evidencialidad, como procedimiento lingüístico, ya que en los textos turísticos encontramos recursos lingüísticos (evidenciales) que codifican los distintos modos en los que se adquiere el conocimiento o la fuente de información. Para ello, hemos utilizado un corpus basado en 50 textos turísticos publicados en la página web de El País durante los años 2013 y 2014. En ellos, analizamos los procedimientos que ha empleado el autor para mostrar los distintos modos con los que ha conseguido la información que expresa en su enunciado, con el fin de persuadir e informar al lector, a través de la modalidad epistémica.

Además, nos encontramos ante el análisis de una lengua de especialidad, el español del turismo, que debido al ámbito en el que nos movemos, tiene un grado de especialización menor que el de otras lenguas de especialidad, lo que hace todavía más enriquecedor el estudio de los evidenciales como recurso lingüístico que manifiesta la modalidad.

Palabras clave: modalidad; evidenciales; español del turismo; pragmática.

\begin{abstract}
:
The aim of this paper is to provide a proposal study based on modality in utterances and its relationship between them and evidentiality, as a linguistic resource, because there are some markers (evidentials) in touristic texts, which coding the knowledge resource and the point of view. This study has a corpus based in 50 tourist texts published in $E l$ País website (between 2013-2014). We analyze the author's linguistic resources to show the way he gets the information appeared in the utterance, in order to persuade and inform the reader, through epistemic modality.

Furthermore, it is a specialized language, Spanish for tourism, which has a lower degree of specialization than other specialized languages, making further interesting the study of evidentials as a modality linguistic resource.
\end{abstract}

Keywords: modality; evidential; Spanish for tourism; pragmatics. 


\section{Introducción}

En este trabajo presentamos un estudio que relaciona la modalidad con la evidencialidad en el español del turismo. Esta unión de hechos pragmáticos se debe a que existe una serie de recursos lingüísticos en español que sirven para codificar los distintos modos en los que se adquiere el conocimiento que aparece en el enunciado, son los marcadores evidenciales. En los textos del español del turismo aparecen frecuentemente estos recursos que muestran la fuente de información de lo que se enuncia y el punto de vista del autor. De ahí que sigamos el siguiente esquema que comienza con una introducción breve al español del turismo (epígrafe 2). Continuaremos explicando qué entendemos por modalidad del enunciado y evidencialidad (epígrafe 3), pasaremos al análisis de los recursos lingüísticos empleados por el emisor (epígrafe 3.1 y 3.2), a su vez, ilustraremos todo ello con ejemplos del corpus basado en textos turísticos publicados en la página web de El País durante los años 2013 y 2014. En ellos, analizamos los procedimientos que ha empleado el autor para mostrar los distintos modos con los que ha conseguido la información que expresa en su enunciado, con el fin de persuadir e informar al lector, a través de la modalidad epistémica. Y, por último, esbozaremos una serie de conclusiones sobre el estudio de este hecho pragmático (epígrafe 4).

\section{El español del turismo y los itinerarios de viaje}

La lengua del turismo está incluida en lo que se denomina lengua de especialidad, es decir, una variedad funcional de la lengua empleada por los especialistas del sector, tanto para comunicarse entre ellos, como para dirigirse al público ${ }^{1}$. En general, las lenguas de especialidad son fácilmente reconocibles porque, aunque se fundamentan en el lenguaje natural, poseen rasgos particulares en diferentes niveles de análisis, sobre todo, el léxico y el sintáctico-semántico ${ }^{2}$. Este hecho se da, principalmente, en lenguas con un marcado carácter hermético, como el lenguaje jurídico, que comparte rasgos en otros idiomas y favorece la labor traductológica. Esta particularidad de los rasgos

\footnotetext{
${ }^{1}$ En este epígrafe asumimos las ideas de Calvi (2006 y 2010) sobre esta lengua de especialidad.

${ }^{2}$ Sobre este tema se puede consultar Alcaraz Varó y otros (2007) y Sanz Álava (2007: 93), que recopilan una serie de trabajos que realizan diferentes estudios sobre el español profesional como lengua de especialidad en distintos niveles y en distintos ámbitos de aplicación.
} 
léxicos y semánticos se obscurece en el español del turismo, ya que engloba distintos sectores y realidades que difícilmente se pueden clasificar y agrupar para establecer características comunes. Sin embargo, los últimos estudios de este ámbito han demostrado que existe una serie de mecanismos, como las estrategias de manipulación de discurso y la creación de neologismos, que favorecen la presencia de un nuevo lenguaje de especialidad: el español del turismo, tal y como afirman Calvi y Mapelli (2011: 10). Este avance del español del turismo en los últimos años ha dado lugar a una gran variedad discursiva en el ámbito turístico, sobre todo en su versión web, que se ha visto incrementada considerablemente, como muestran publicaciones recientes Sanmartin (ed.) (2012 y 2014). Dicho incremento ha dado lugar a nuevos términos como cibergénero o Turismo 2.0, que comprende tanto blogs de viajeros, como foros de viajes, wikis de viajes, etc.

Por tanto, en este trabajo, estudiamos español del turismo centrado en la temática de especialidad que poseen los textos analizados, en la modalidad que manifiestan y en la función lingüística principal que presentan, dentro de un corpus concreto extraído del El País. El Viajero.

Nuestro corpus de ejemplos se ha extraído del análisis de 50 textos publicados en la web de El País. El Viajero. Estos textos, al igual que todos los géneros textuales turísticos ${ }^{3}$, presentan un continuum entre el grado máximo de persuasión y mínimo de información, como ocurre, por ejemplo, en un anuncio publicitario, hasta el grado mínimo de persuasión y máximo de información, como sucede en una guía turística (Calvi y Mapelli, 2011: 37). En nuestro caso, estamos ante itinerarios de viaje de carácter periodístico, publicados en Internet, que, en general, describen una lista de datos referentes a un viaje y proponen una serie de actividades para seguir, tal y como afirma Ares (2011: 133). El emisor de este tipo de textos es un especialista en la materia, posiblemente un periodista, por el medio de difusión en el que nos encontramos, especializado en viajes, que pretende orientar a su lector ${ }^{4}$, en general, no especializado en la materia, que solo busca una lectura interesante, o elegir un determinado hecho relacionado con sus vacaciones, como puede ser hotel, excusiones,

\footnotetext{
${ }^{3}$ Sobre tipos de géneros textuales, véase Suau (2012: 127) y Calvi (2010), entre otros.

${ }^{4}$ Véase Dann (1996: 6-23) para las principales teorías sociolingüísticas sobre la construcción del texto turístico.
} 
lugares, etc. La finalidad que persigue el emisor está asociada con la motivación comunicativa de todo enunciado, es decir, por qué se dice, y qué efectos puede producir en el receptor, esto es, para qué se dice, puesto que su intención es sugerir y convencer. Los textos analizados presentan una variedad de funciones y recursos. Entre sus funciones destacamos la procedimental, la directiva y la argumentativa, que sirven para modificar la actitud del lector. Así, mediante estas funciones, el emisor desea sugerir al lector un itinerario específico y convencerle de algo relacionado con su viaje. Las funciones concretas de este tipo de textos turísticos son informar, aconsejar y dirigir ${ }^{5}, \mathrm{y}$ como observamos, se trata de una gran variedad de finalidades, que responden a diferentes secuencias textuales: argumentativa, expositiva, descriptiva, etc. De ahí que, como hemos dicho anteriormente, la mejor manera de estudiar estos textos turísticos sea atendiendo a cuestiones concretas y particulares. En nuestro caso, nos basaremos en los recursos lingüísticos que utilizan para mostrar la fuente de conocimiento y la relación que este hecho tiene con la modalidad que presentan, es decir, con la manifestación del emisor ante el enunciado. De ahí que, a continuación, expliquemos qué entendemos por estos hechos pragmáticos (Ruiz Gurillo, 2006: 57).

\section{La modalidad del enunciado y la evidencialidad}

En los textos turísticos analizados nos interesa estudiar cómo se manifiesta el emisor ante el enunciado y qué recursos emplea para mostrar el origen de su conocimiento; por eso, nos basaremos en la modalidad que presentan y en los marcadores evidenciales que utilizan. Entendemos modalidad como categoría semántica referida al campo de la lingüística y, concretamente, a la Teoría de la Enunciación; y evidencialidad como procedimiento lingüístico que sirve para codificar la modalidad (Alvarado, 2010: 64-66). Veremos, a continuación, cada uno de ellos ilustrados con ejemplos de los textos.

\footnotetext{
${ }^{5}$ Dann (1996: 35) ya establecía algunas pautas para delimitar las funciones en los textos turísticos.
} 


\subsection{La modalidad del enunciado}

Para Otaola (1988: 99), la modalidad discursiva es "la actitud del sujeto hablante ante el oyente y/o ante el contenido de la predicación emitida por él en el enunciado" y distingue dos tipos de modalidad: la modalidad de la enunciación y la modalidad del enunciado. La primera, expresa la actitud del hablante con respecto al oyente, mientras que la segunda muestra la actitud del hablante con respecto al enunciado. Nos centramos en este segundo tipo de modalidad en la que el hablante puede expresar una relación valorativa, matizar una aserción, etc. De ahí que tengamos diferentes tipos de modalidad del enunciado: las modalidades lógicas, que expresan el grado de certidumbre, probabilidad y posibilidad de lo que se enuncia, y las modalidad apreciativas o subjetivas, que muestran la actitud del hablante.

Por tanto, en las modalidades lógicas encontraremos la relación entre modalidad y evidencialidad, puesto que se relaciona con la verdad del dictum. Distinguimos tres clases de modalidad lógica que tienen su correspondencia en el plano lingüístico (Lyons, 1989 [1977]: 719; Otaola, 2006: 171; Ruiz Gurillo, 2006: 64):

- Modalidad alética es aquella que indica la verdad o falsedad de un enunciado, lo necesario y lo posible.

- Modalidad epistémica es aquella que se vincula con el ámbito de la posibilidad de que un enunciado sea cierto, es decir, expresa certidumbre y el grado del compromiso del hablante con lo que dice.

- Modalidad deóntica es aquella que expresa la obligatoriedad de que se cumpla lo que el hablante dice.

Ilustraremos con ejemplos cada una de estas modalidades en los textos analizados. En (1) tenemos un ejemplo de un texto que propone 10 hoteles españoles para el verano:

(1) Desde tierra, franqueado el arco oriental de la entrada, cuesta imaginarse un hotel tan metido en el mar como este. Desde el agua, imposible saber si el hotel flota o se abalanza hacia el mar. No hay playa. Hay hotel. 
En (1) se utiliza el adjetivo imposible como recurso lingüístico para mostrar modalidad alética y destacar una de las cualidades verdaderas que tiene el hotel, que está pegado al mar; sin embargo, no se está utilizando con su función prototípica que tiene que ver con el ámbito de lo real, lo posible, sino, con un uso particularizado e irónico, ya que cualquier lector sabe que está ante una hipérbole (imposible saber si el hotel flota o se abalanza hacia el mar).

En (2) aparece un fragmento sobre un texto que describe la zona de Huelva y el Coto de Doñana:

(2) Resulta admirable la competencia ornitológica de Miguel Ángel Jiménez, guía de Doñana Nature, a la hora de vislumbrar águilas calzadas, abubillas, calamones... quizá linces. La finca Coto del Rey es otra de las zonas a visitar.

(El Pais. El Viajero "Huelva, la costa secreta", 11/07/13)

En (2) aparece el adverbio quizá que está relacionado con el saber, con la cantidad de conocimiento que posee el emisor sobre el tema y con el grado de certeza que manifiesta con respecto a lo que está diciendo, es decir, con la modalidad epistémica. En este caso, el emisor duda de que se puedan ver o no linces entre los animales que hay en Doñana, pero lo destaca como una de las cualidades del Coto.

En (3) seguimos con el texto de Huelva que, en esta ocurrencia, se trata el tema gastronómico:

(3) En Huelva hay varias cosas que deberían ser pecado mortal. Una es no probar — con el típico carraspeo de garganta - el jamón ibérico de bellota (marcas: 5 Jotas o Jabujo de Ley).

(El País. El Viajero "Huelva, la costa secreta", 11/07/13)

En (3) aparece la perífrasis de obligatoriedad "deber + infinitivo" para mostrar la obligatoriedad de que se cumpla lo que el hablante dice, esto es, expresa modalidad deóntica. Este recurso se ha utilizado en el fragmento como hipérbole (pecado mortal) para destacar las cualidades del jamón de Huelva. 
En estos textos de El País. El Viajero analizados observamos que aparecen numerosos recursos lingüísticos que manifiestan las diferentes modalidades del enunciado, alética, epistémica y deóntica, puesto que la finalidad de este tipo de textos es informar, sugerir y convencer de que lo que se está diciendo es verdad, y la huella del emisor está presente en los fragmentos.

\subsection{La evidencialidad}

Entre todo el acervo de formas lingüísticas que pueden expresar la modalidad, encontramos la evidencialidad. La evidencialidad es un procedimiento que sirve para codificar lingüísticamente la modalidad (Alvarado, 2010: 66; Aikhenvald y Dixon, 2003). Esta categoría semántica está relacionada con los distintos modos con los que el hablante ha conseguido la información que expresa en su enunciado (Bermúdez, 2005: 19). Estos modos pueden ser directos, si el hablante consigue la información a través de sus sentidos o si describe sensaciones, o indirectos, si el hablante no tiene acceso de primera mano a la información. Los tipos de evidencialidad los resumimos en el siguiente cuadro tomado de Dendale y Tasmowski (2001: 343):

\begin{tabular}{|l|l|l|l|}
\hline \multirow{2}{*}{ Tipos de Evidencia } & Directa & Atestiguada & Percibida por sentidos. Sensaciones \\
\cline { 3 - 5 } & \multirow{2}{*}{ Indirecta } & Reproducida & De segunda o tercera mano. Del folclore \\
\cline { 3 - 4 } & & Inferida & Como resultado o razonamiento \\
\hline
\end{tabular}

Tabla 1. Tipos de evidencialidad tomado de Dendale y Tasmowski (2001: 343)

En la tabla 1, los autores proponen dos tipos de evidencia, directa o indirecta, según el modo en el que el hablante perciba la información. Estos tipos tendrán, a su 
vez, subclases de evidencia, que dependen de si la información ha sido recibida por los sentidos, si es de segunda o tercera mano o si es el resultado de un razonamiento. Al tiempo que sirven para mostrar la fuente de información, muestran el compromiso del hablante ante lo dicho. De esta manera, tenemos formas lingüísticas llamadas evidenciales que expresan el modo en el que se ha adquirido el conocimiento de lo enunciado y manifiestan los diferentes tipos de modalidad como:

- Evidenciales que expresan modalidad alética: verdaderamente, no puede ser, parece que...

- Evidenciales que expresan modalidad epistémica: por supuesto, desde luego, ya te digo...

- Evidenciales que expresan modalidad deóntica: necesariamente, obligatoriamente...

Con esta idea asumimos que hay valores evidenciales que están codificados en español para expresar diferentes tipos de modalidad (Otaola, 1988; Martín Zorraquino, 2001, o Ruiz Gurillo 2006, entre otros), tal y como vamos a apreciar en los ejemplos analizados a continuación.

Observemos, por tanto, algunos ejemplos de nuestro corpus en los que aparecen diferentes marcadores evidenciales. En (4) continuamos con el texto que describe los rincones de Huelva, aunque ahora presenta el pueblo de Niebla y su valor artístico:

(4) En el mihrab una cruz parece querer marcar el territorio cristiano. Dentro del castillo (visitable) tiene lugar el Festival de Teatro y Danza.

(El País. El Viajero "Huelva, la costa secreta", 11/07/13)

En (4), parece indica un caso de evidencia indirecta inferida, ya que el emisor no tiene acceso directo al conocimiento de la situación descrita, pero puede inferir lo que ocurre a partir del contexto situacional. Se trata, por tanto, de un evidencial que expresa modalidad alética, que tiene que ver con lo necesario y lo posible. Es posible que la cruz esté marcando el territorio cristiano.

En (5) encontramos un ejemplo del texto que promociona 10 hoteles españoles para el verano: 
(5) Las habitaciones respiran a maderas de Java y estampados tailandeses, así como en los cuartos de baño los kimonos japoneses sustituyen a los albornoces mediterráneos. Por supuesto, la cocina es de fusión asiática.

(El País. El Viajero "10 hoteles españoles para el verano”, 10/06/13)

En (5), el emisor utiliza la fórmula rutinaria por supuesto porque está completamente seguro de su enunciado, la cocina es de fusión asiática, y, por tanto, muestra certeza epistemológica. En este caso, se trata de una enumeración de detalles asiáticos del hotel y la cocina también forma parte de él, por lo que la gastronomía es asiática. Por tanto, es una evidencia directa, puesto que se ha comprobado por su experiencia personal.

En (6) aparece un fragmento del texto en el que se hace una entrevista al chef de Módena, Bottura, que se encuentra en el mercado, observa los productos y habla del vinagre que lleva el mismo nombre de la ciudad:

(6) Bottura corre hacia un puesto y se hace con una botellita de vinagre denso y pegajoso. "Lleva 25 años fabricar 100 miligramos”, dice mientras inclina el frasquito. El líquido apenas se mueve.

(El País. El Viajero "El hombre de Módena”, 31/05/13)

En (6), con las palabras de Bottura se infiere la necesidad de que el enunciado sea cierto, ya que es un experto cocinero del lugar el que está manifestando esa opinión. Así pues, el verbo decir tras la aserción lleva 25 años fabricar 100 miligramos sirve para que el receptor crea firmemente esas palabras, dadas por el chef. Por tanto, funciona como un evidencial de tipo indirecto y reproducido, que expresa modalidad deóntica, es decir, la obligatoriedad de creer lo que está diciendo, ya que reproduce con sus palabras lo que le ha dicho el chef.

Los evidenciales de tipo indirecto con la evidencia reproducida también pueden manifestar modalidad epistémica. Veamos (7), en el que se trata el tema del atardecer en Huelva:

(7) Para presenciarlo, unos recomiendan el faro de Matalascañas o la terraza del parador de Ayamonte, viendo cómo cae el disco rojo junto al puente internacional. Visto que en verano cae el 
sol en tierra, o buscamos la punta de la Canaleta en Punta Umbría o acudimos al Club Mandala, que ofrece atardeceres exclusivos sobre las marismas del Odiel.

(El País. El Viajero "Huelva, la costa secreta”, 11/07/13)

En (7), la utilización de unos y visto que ayudan al emisor a mostrar cautela sobre la información que está dando, ya que manifiesta que lo que va a decir no es un conocimiento directo de primera mano y atestiguado, sino que es un conocimiento indirecto y reproducido, tomado de terceras personas o del saber común sobre el atardecer en Punta Umbría.

En muchas ocasiones, los ejemplos de modalidad que encontramos se encuentran relacionados en el mismo fragmento, debido a la finalidad que tiene el texto y a quién va dirigido. Observemos (8) en el que se ha extraído un fragmento del texto de Huelva. En él aparece reflejado tanto la modalidad subjetiva evaluativa como la modalidad lógica:

(8) El mejor momento es el atardecer —incluso bajo la luna-y el punto de destino puede ser la torre del Loro. Para apuntarse no es necesario tener experiencia.

(El País. El Viajero "Huelva, la costa secreta", 11/07/13)

En (8) el adjetivo en grado superlativo mejor manifiesta la modalidad subjetiva, ya que el emisor muestra su actitud ante el enunciado. Seguidamente, observamos que aparece la perífrasis verbal poder ser que refleja la modalidad alética, tiene que ver con posibilidad de que el enunciado sea cierto, se trata de un evidencial indirecto inferido, puesto que no se tiene acceso directo a la verdad del enunciado. Por último, el emisor enuncia no es necesario que expresa modalidad deóntica, ya que muestra su conocimiento sobre el tema utilizando un evidencial indirecto inferido. Así, en este fragmento aparecen varios tipos de modalidad del enunciado con distintos tipos de evidencia.

Por último, destacaremos los evidenciales de tipo directo atestiguado, que son muy comunes en este tipo de textos, ya que pretende convencernos de algo a través de su propia experiencia. Todos los evidenciales de este tipo encontrados en nuestros 
textos manifiestan o la modalidad epistémica, tal y como hemos visto en (5), o la modalidad subjetiva evaluativa, ya que pretende mostrar la veracidad de lo enuncia o dar su opinión y valoración a partir de lo que ha percibido por sus sentidos, tal y como observamos en (9), fragmento extraído de la descripción de los 10 hoteles españoles:

(9) Antes de irse a la cama, una excursión por el bar terraza sirve para entablar una animada conversación con Margarita, está linda la mar.

(El País. El Viajero “10 hoteles españoles para el verano”, 10/06/13)

En (9) vemos cómo el emisor reproduce de forma directa las palabras que mantuvo con la dueña del hotel y califica su conversación con el adjetivo calificativo animada, para mostrar su punto de vista y desde su experiencia personal. Así, muestra al lector el trato familiar que mantuvo en dicho hotel para convencerlo de que vaya en sus vacaciones.

\section{Conclusiones}

Una vez realizado el análisis de los fragmentos propuestos, según el tipo de modalidad del enunciado que presentan y su relación con la evidencialidad, podemos extraer una serie de conclusiones sobre el uso de los recursos lingüísticos empleados en los textos turísticos, ya que todos ellos se utilizan para sugerir y convencer al lector de que seleccione determinados itinerarios de viaje, es decir, intenta influir en la toma de decisiones, función propia de este tipo de textos.

Además, hemos visto que uno de los recursos más utilizados en nuestro corpus son los evidenciales, tal y como vemos en la tabla 2 :

\begin{tabular}{|l|l|l|l|}
\hline \multicolumn{2}{|c|}{ Tipos de evidencia } & Modalidad y ocurrencias analizadas \\
\hline & Directa & Atestiguada & $\begin{array}{l}\text { Modalidad lógica epistémica (5) } \\
\text { Modalidad subjetiva evaluativa (9) }\end{array}$ \\
\hline
\end{tabular}




\begin{tabular}{|l|l|l|l|}
\hline Tipos de Evidencia & & Reproducida & $\begin{array}{l}\text { Modalidad lógica deóntica (6) } \\
\text { Modalidad lógica epistémica (7) }\end{array}$ \\
\cline { 3 - 4 } & Indirecta & Inferida & $\begin{array}{l}\text { Modalidad lógica deóntica (8) } \\
\text { Modalidad lógica epistémica (8) } \\
\text { Modalidad subjetiva evaluativa (8) }\end{array}$ \\
\hline
\end{tabular}

Tabla 2. Evidenciales y modalidad

Los tipos de evidencia que se puede manifestar a través de evidenciales lingüísticos codifican la modalidad del enunciado vista anteriormente. Así, de los ejemplos analizados, destacamos que los tipos de evidencia directa e indirecta son muy comunes entre los itinerarios de viaje, ya que pretenden convencer al lector de algo, por eso es importante destacar que lo que se presenta en los textos del El País. El Viajero se ha experimentado de forma directa o indirecta. Este hecho explicaría el siguiente gráfico que muestra los porcentajes de aparición de evidenciales en nuestro corpus completo:

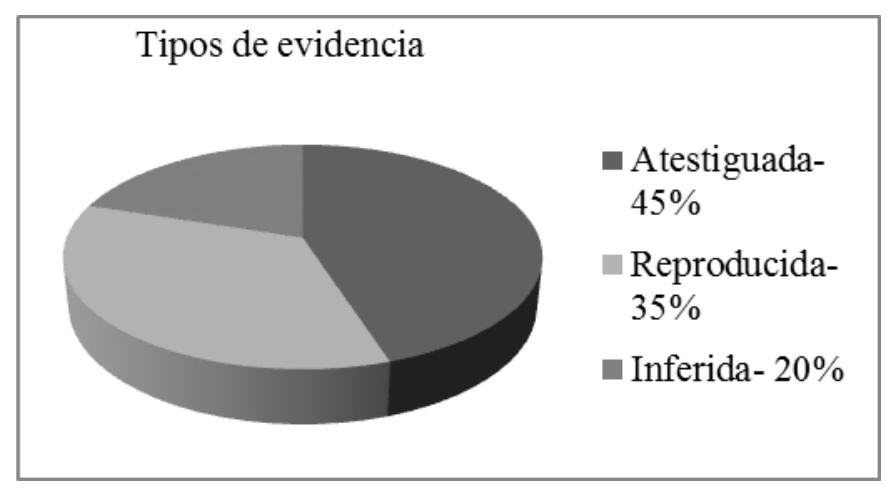

Gráfico 1. Porcentajes de evidenciales en el corpus 
Según el gráfico ${ }^{6}$, podemos interpretar que los evidenciales que muestran la información de forma directa y atestiguada son los que mayor porcentaje presentan en el corpus, el 45\% de los datos, ya que el emisor pretende mostrar que la importancia de su enunciado y la veracidad del mismo radica en su experiencia personal, como en (5). De este modo, la información resulta más creíble para su lector. El segundo grupo de evidenciales que aparece con mayor frecuencia en el corpus es el que muestra evidencia indirecta reproducida, el 35\% de los datos, puesto que la fuente de su conocimiento se encuentra en terceras personas que han mostrado certeza en la información que se enuncia, así sucede, por ejemplo, en la ocurrencia (6), en el que se muestra una entrevista narrada. Por último, aparece con un $20 \%$ de los datos, los recursos que presentan evidencia indirecta inferida, porque el conocimiento se ha producido como resultado de un razonamiento, que es el procedimiento menos habitual para conseguir su finalidad, que es convencer al lector de que lo que está contando, como en (8).

Por todo ello, podemos concluir este análisis afirmando que los textos de El País. El Viajero dejan ver la huella del emisor y su conocimiento, a partir de estos modos de modalización que se materializan por medio de diferentes recursos lingüísticos, como los evidenciales.

El trabajo que hemos presentado en este artículo abre futuras vías de investigación que están marcadas por el carácter del corpus recogido, por los destinatarios y por la finalidad que presentan.

\section{Referencias bibliográficas}

Aikhenvald, A. Y. y R. M. W. Dixon (eds.), 2003: Studies in evidentiality, Amsterdan y Philadelphia: John Benjamins.

AlCARAZ VARÓ, E. y otros (eds.), 2007: Las lenguas profesionales y académicas, Barcelona: Ariel.

Alvarado Ortega, M. B., 2010: Las fórmulas rutinarias en el español actual, Frankfurt: Peter Lang.

\footnotetext{
${ }^{6}$ Los datos que se muestran sobre los evidenciales en el gráfico corresponden a los que se han extraído del corpus completo de 50 textos de El País. El Viajero.
} 
Ares ARes, A., 2011: "La deixis y la modalización discursiva en los itinerarios de viaje periodísticos" en M. V. CALVI y G. MAPELli (eds.): La lengua del turismo: Géneros discursivos y terminología, Bern: Peter Lang, 131-152.

Bermúdez, F. G., 2005: Evidencialidad. La codificación lingüistica del punto de vista, Estocolmo: Universidad de Estocolmo (tesis doctoral inédita).

CAlvi, M. V., 2006: Lengua y comunicación en el español del turismo, Madrid: Arco Libros.

CAlvi, M. V., 2010: "Los géneros discursivos en la lengua del turismo: una propuesta de clasificación", Ibérica 19, 9-32.

Calvi, M. V. y G. Mapelli (eds.), 2011: La lengua del turismo: Géneros discursivos y terminología, Bern: Peter Lang.

Dann, G., 1996: The language of tourism. A Sociolinguistic Perspective, Oxon: Cab International.

Dendale, P. y L. TASMOWSKI, 2001: "Introduction: evidentiality and related notions", Journal of Pragmatics 33, 3, 339-348.

LyONS, J. 1989 [1977]: Semántica, Barcelona: Teide.

MARTín ZorRaquino, M. A., 2001: "Marcadores del discurso y estrategias de cortesía verbal en español” en M. I. MontoyA (ed.): La lengua española y su enseñanza, Granada: Universidad, 55-74.

Otaola Olano, C., 1988: "La modalidad (con especial referencia a la lengua española)", Revista de filología española 68:1/2, 97-117.

Otaola Olano, C., 2006: Análisis lingüístico del discurso. La lingüística enunciativa, Madrid: Ediciones académicas.

Ruiz Gurillo, L., 2006: Hechos pragmáticos del español, Alicante: Servicio de Publicaciones Universidad de Alicante.

SuAU JiMÉnEZ, F., 2012: "Páginas web institucionales de promoción turística: El uso metadiscursivo e interpersonal en inglés y español” en J. SANMARTín (ed.): Discurso turístico e Internet, Frankfurt: Iberoamericana, 125-153.

SANMARTín, J., (ed.), 2012: Discurso turístico e Internet, Frankfurt: Iberoamericana.

SANMARTíN, J., (coord.), 2014: Norma: Cibergéneros y estrategias pragmalingüísticas en el turismo 2.0. Valencia. 
ONOMÁZEIN 33 (junio de 2016): 327-342

Belén Alvarado Ortega:

Enunciación y percepción: la evidencialidad en los textos turísticos del español

Sanz Álava, I., 2007: El Español Profesional y Académico en el aula universitaria: El discurso oral y escrito, Valencia: Tirant lo Blanch.

\subsection{Enlaces a internet}

El País. El Viajero: http://elviajero.elpais.com/elviajero/ 